\title{
Hoping to Stop Covering the Sky with One's Palm: It's Time to Go Back to Vernacular Spirit
}

\author{
Eunjoo Lee* \\ Department of Architectural Engineering, South Korea \\ *Corresponding author: Eunjoo Lee, Department of Architectural Engineering, South Korea
}

Submission: 㥏 December 08, 2018; Published: 㭰 December 12, 2018

\begin{abstract}
There is an old saying in my country, 'covering the sky with one's palm'. It refers to when someone is pretending to avoid something unavoidable in vain. It can also be referred to as trying to avoid the cry of the earth under powerful and efficient air conditioner inside a brilliant glass building but modern society can't go back to what it was before the industrialization. Eventually modern human society should do something more meaningful for our survival. For instance, as adopting the merit of hunter-gatherer's life, it is imperative that modern architecture industrially succeed to the architectural assets initiated from prehistoric wisdom. That is, to utilize developed modern architectural technology to interpret and apply the advantages of the vernacular spirit out of the architecture from the past. This needs to be executed now more than ever, before the palms burn to ashes in the sun.
\end{abstract}

\section{Opinion}

On the 4th of last August, my old air-conditioner, which had been making a suspicious noise for days, finally crossed the Jordan River. Undergoing precedentless heat wave reaching near $40{ }^{\circ} \mathrm{C}$ for almost 3 weeks, service engineer adamantly declared that my conditioner had no chance of working again, since its spare parts weren't manufactured any more. Then, at the home appliance mall, the clerk announced that it took at least four weeks to get a new airconditioner, due to the explosive demand on it, with an impassive look. Since then, I and my family had a painful life in despair for more than two weeks, failed to be free from agony of loss of our air-conditioner.

Last summer was harsh for every human residence in northern hemisphere more than ever before. It was actually been noticed why the earth has been such fickle for years and people have made an effort, or at least, have acknowledged that something should be done to lessen the pain towards ourselves and the Earth where we belong. However, a quarter of a century after the Rio Summit in 1992, it becomes evident that the method, scale and pace of effort we've made need to be reconsidered. The Paris Climate Agreement in 2015 represented another evidence of global sympathy on this point.

The Paris Climate Agreement stressed on the previous longterm goal of temperature constraint from $2{ }^{\circ} \mathrm{C}$ to $1.5^{\circ} \mathrm{C}$ compared to the period before industrialization. Apart from detailed guidelines in respective scope, still discussing in, I tried to presume what condition before industrialization can be the specific objective in the scope of architecture. Then, a symbolic scene came across my mind that a high-rise building consisting of glass, steel and concrete, and a shiny city filled with those skyscrapers in high density. If so, is it the goal that dismissed the megalopolis and its populations, insisting dugout hut, adobe buildings, like rewinding movie film? I know, it is nonsense. In the fields of architecture and construction, a significant level of effort on environmental factors had been focused on improving energy efficiency of buildings, still built in accustomed fashion of modern architecture. It seems, in a manner, just like sticking to unhealthy lifestyle and dietary only by substituting soda for orange juice, ignoring critical symptoms of serious illness. In fact, it is time to require radical change in entire lifestyle and dietary with painful effort of controlling ourselves, moreover, quite deal of self-sacrifice.

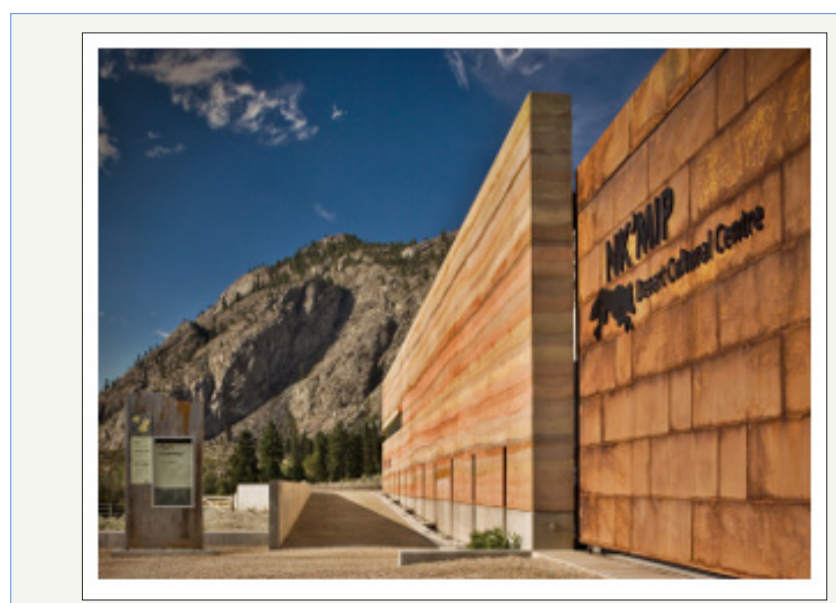

Figure 1: Cultural center building in earth. 
Likewise every other human artifact, architectural structure consumes energy from the stage of collecting raw material of it to that of destroying it. The higher technology or the more sophisticated design a building with, the more embodied energy needed. A forest with triumphant glass towers in the middle of desert, or transparently glittering gemlike cityscape at night is the contemporary trophy of wealth and pride accomplished by successful industrialization. But it is quite ironic that people love cities with old-fashioned mood.

Old cities under different civilizations before the industrialization, developed their own vernacular architecture. A good number of studies have already proved their excellence in a modern scientific perspective. However, we are not eager to apply that eminence, because it appears to be conventional, and it doesn't resemble state-of-the-art. To my regret, as the society was the latecomer in industrialization, it seemed to hastily relegate its architectural vernacular legacy to the annals of history, then introduced the shiny newest buildings that devoured energy and resources just like a black hole. No one can blame them. Nonetheless, it reminds me the marching of lemmings.

Adding more saying about the dietary and lifestyle, it is said that Homo sapiens i.e., modern human beings have completed current gene structure for about 2.6 million years, and that the gene structure has not yet perfectly adapted to the dietary and lifestyle changes that have happened since the agricultural revolution about
10,000 years ago. This fact explains why modern human beings are suffering from different diseases from the past, despite of their plentiful life. However, even for the sake of health, modern people cannot live like hunter-gatherers before the agricultural revolution. So, we cannot but try to revive the advantages of lifestyle of those times in a different i.e., modern way. It can be in a way like trying to repudiate the temptations of many unhealthy foods that fascinate the tongue, nose, and eyes (even the ears!), or swallowing strange foods that one would never look at without the reason for good health. Or, it can be the way that getting out of the couch unwillingly and sweating on purpose. For the sake of survival, it's inevitable.

There is an old saying in my country, 'covering the sky with one's palm'. It refers to when someone is pretending to avoid something unavoidable in vain. It can also be referred to as trying to avoid the cry of the earth under powerful and efficient air conditioner inside a brilliant glass building but modern society can't go back to what it was before the industrialization. Eventually modern human society should give up more things that have been taken for granted, otherwise, should do something more meaningful for our survival. For instance, as adopting the merit of hunter-gatherer's life, it is imperative that modern architecture industrially succeed to the architectural assets initiated from prehistoric wisdom. That is, to utilize developed modern architectural technology to interpret and apply the advantages of the vernacular spirit out of the architecture from the past. This needs to be executed now more than ever, before the palms burn to ashes in the sun.

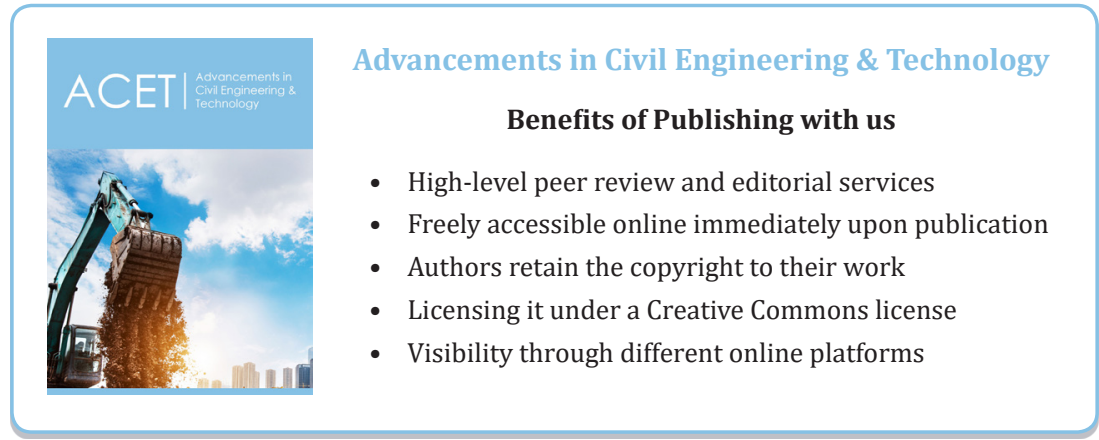

